\title{
ESTIMATING OF ROAD ACCIDENTS DURING THE COVID-19 PANDEMIC YEAR IN ALBANIA
}

\author{
Raimonda Dervishi $^{{ }^{*}}$, Julian Kasharaj ${ }^{2}$, Igli Kondi ${ }^{2}$ \\ ${ }^{1 *}$ Polytechnic University of Tirana, Faculty of Mathematical and Physical Engineering, Tirana, Albania; \\ ${ }^{2}$ Polytechnic University of Tirana, Faculty of Civil Engineering, Tirana, Albania; \\ *Corresponding Author Raimonda Dervishi, e-mail: raimondadervishi@yahoo.com;
}

Received April 2021; Accepted May 2021; Published June 2021;

DOI: $\underline{\text { https://doi.org/10.31407/ijees11.318 }}$

\begin{abstract}
The year 2020 designated as the year of the Covid-19 pandemic, has not limited the fatalities of road accidents worldwide, including Albania. In this paper we focus to analyze the accidents data from the data reported by Instat website over this year and to estimate whether this pandemic has affected to the number of road accidents and fatalities in our country. As in many other countries there is a noticeable decrease in road accidents during this year, but at the same time it seems that the number of fatalities in proportion to the reduction of accidents has not fallen. We argue that it is possible to apply Chi-Square approach and also Odss Radio approach to better identify the significant factors which affect road accidents. Furthermore through these statistical approaches we have studied the significant relation between the factors and the fatalities that occurred during 2020. It is evidenced that gender, age and months are significant factors in our accidents data; there is also a predominance of men gender in fatalities compared to women gender as well as drivers more than pedestrians. Given the rapidly increasing of lost lives in proportion to road accidents that are a major challenge for the health system, we recommend that more emphasis placed on the use of statistical methods - in the search for road safety by government researchers and road safety experts.
\end{abstract}

Keyword: Statistical approach, road accidents, road accident fatalities, significant factors. 